\title{
THE BEST/GOOD PAPER AWARDS 2012
}

It is our great pleasure to announce hereunder the winners of the Best/Good Paper Awards 2011. The winners have been selected by the Laser Therapy International Editorial Board and the Editorial Team who screened the papers in all the issues of Volume 20, 2011. We heartily congratulate the selected winners, and are delighted to recognize their achievement through the presentation of the prize-money and certificates. The final decision of the Board is as follows:
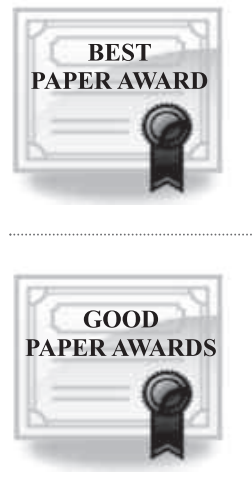

REDUCTION OF INTERLEUKIN-6 EXPRESSION IN HUMAN SYNOVIOCYTES AND RHEUMATOID ARTHRITIS RAT JOINTS BY LINEAR POLARIZED NEAR INFRARED LIGHT (SUPERLIZER) IRRADIATION

Hidefumi Araki, Asayo Imaoka, Noboru Kuboyama, Yoshimitsu Abiko

DIAMOND SHAPED OPTICAL FIBER DELIVERY SYSTEM

Haim Mnitentag, Alexander Gersten, Shlomo Walfisch

LOW LEVEL LASER THERAPY ON EXPERIMENTAL MYOPATHY

Soledad Dávila, María Belén Vignola, David Cremonezzi, Juan C. Simes, Fernando Soriano, Vilma R. Campana

The quality of the selected papers was extremely high, and it was very difficult for all the members of the Editorial Board to make a definitive decision regarding the 'Best' and 'Good' papers.

That's the awards for Volume 20 of the journal awarded, and we are now in Volume 21, and 2012!! To see how you can get YOUR paper entered for this year's awards, please see the following announcement and get writing! Good luck with your submission, and we look forward to each and every one.

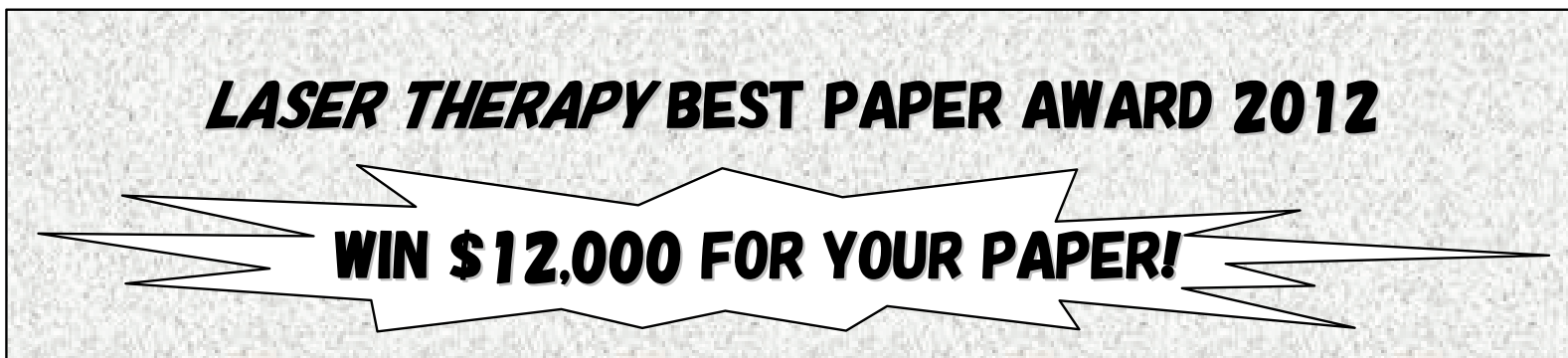

The LASER THERAPY team is seeking submissions of papers for the $21^{\text {st }}$ volume of the 2012 issues. The team is placing $1,600,000 \mathrm{JPY}(19,200 \mathrm{USS} *)$ to grant to the authors whose papers are selected as the most supreme among all the submitted papers. The winner of the Best Paper Award will be offered 1,000,000 JPY (12,000 US\$*) and two winners for the Good Paper Awards will be presented with 300,000 JPY (3,600 US\$*) each.

For more information or submission, contact:

E-mail: lasertherapy@jmll.co.jp / Tel: +81-(0)3-5269-1403 / Fax: +81-(0)3-5269-1410 Japan Medical Laser Laboratory, Shinsei-Kaikan Bldg. 4F, Shinanomachi 33-2 Shinjuku, Tokyo 160-0016 JAPAN

We are looking forward to receiving your outstanding papers! 